\title{
A CONSTRUÇÃO SOCIAL DO SABER SOBRE SAÚDE E DOENÇA: UMA PERSPECTIVA PSICOSSOCIAL*
}

Mary Jane P. Spink **

O texto explora as possíveis contribuições da Psicologia Social para a compreensão do processo de adoecimento $\theta$ das práticas sócio-médicas organizadas em torno deste fenômeno. Situa inicialmente a perspectiva epistemológica construtivista na Psicologia Social. A partir desta ótica, analisa as contribuições da Psicologia para a descrição e explicação do binômio saúdedoença, identificando aí três vertentes distintas: a intra-individual, a psicossocial - a construtivista. Conclui apontando para a relevância da perspectiva construtivista dada a expansão do quadro de referência que passa a englobar, também, o conhecimento do senso comum dos usuários dos serviços de saúde.

Ao abordar as contribuições possíveis da Psicologia Social para a compreensão do processo de adoecimento e das práticas adotadas para a prevenção deste adoecer, sua cura ou a promoção do estado de saúde, partiremos, neste ensaio, de uma concepção psicossocial bastante especffica. Concepção esta que é fruto de todo um processo de questionamento que perpassa não apenas esta

* Versão modificada da conferência proferida no 12 Seminário de Psicologia Social e Saúde Pública, realizado na Faculdade de Saúde Pública da Universidade de São Paulo, 19-20 de outubro de 1989.

** Docente do Programa de Estudos Posgraduados em Psicologia Social Pontifícia Universidade Católica de São Paulo 
disciplina mas, de forma mais geral, inaugura uma nova epistemologia nas ciências como um todo e nas ciências sociais de forma mais incisiva.

Esta perspectiva, construtivista e historicista por excelência, tem como precursores, como aponta IBANEZ (1990)(8), Nietzsche passando por Heidegger, pelo Wittgenstein da segunda fase e por Foucault. Consiste, essencialmente, em uma tentativa de desmontar 0 arcabouço epistemológico de retórica da verdade pautada pela razão cientffica, enfatizando, em marcada oposição a esta postura, a natureza "construlda" da realidade social. Ou seja, muito embora a objettvidade possivel do "mundo das coisas" não seja posta em dúvida (realismo ontológico), as nossas explicações e descrições deste mundo são tidas como construções socialmente determinadas. Desta forma, o discurso e a própria prática cientffica podem e devem ser eles próprios objetos de uma análise social.

A conseqüência mais visłvel desta postura é a adoção necessária de uma perspectiva historicista dado que "toda produção que emana de seres históricos tem as condições de sua produção nelas incorporadas" (IBANEZ, 1990 (8), p. 11). Ou seja, elas são sempre contingentes às condições concretas particulares que as engendraram e tornaram possivel sua disseminação em um determinado grupo social.

A ótica construtivista, em última análise, acaba gerando uma visão mais integrada e compreensiva das ciências sociais, sendo a fragmentação atual em disciplinas relativamente estanques vista igualmente como produto de uma construção especffica, historicamente datada, de ciência. Assim, embora tomando como ponto de partida uma perspectiva especffica - tal como a da Psicologia Social cada vez mais se torna imprescindivel cruzar e recruzar fronteiras disciplinares em um processo contínuo de desterritorialização. Afinal, como afirma ROLNIK (17)(1989: 16)" o cartógrafo é sobretudo um antropófago" e as cartografias "trazem marcas dos 
encontros que as foram constituindo: sinais dos estrangeiros que, devorados, desencadearam direções na sua evolução".

A Psicologia Social, tendo como arena de atuação o complicado meio de campo entre a esfera individual e social, tem necessariamente - pela própria constituição de seu objeto de estudo - esta vocação antropofágica; ou, usando uma linguagem menos "pós-moderna", tem evidente vocação interdisciplinar, sendo suas fronteiras permeáveis às contribuições de uma variedade de outras disciplinas afins. Vocação esta que já foi negada em certas fases de sua história, quando foram privilegiadas vertentes mais intra-individuais; mas foi reassumida, a partir dos anos setenta, quando psicólogos mais crticos passaram a exigir uma "Psicologia Social mais social". (TAJFEL, 19, 1982).

Nesta nova perspectiva caberia à Psicologia Social, como afirma Lane (11)(1984), recuperar o indivíduo na intersecção de sua história com a história de sua sociedade. Abandonar, portanto, a dicotomia indivíduo-sociedade retomando, em uma nova base, o debate sobre a autonomia relativa das esferas social e individual sem cair no reducionismo sociologizante (quando o indivíduo é visto como produto do mundo social que o cerca) ou psicologizante (quando, em última análise, o indivíduo é visto como um ser autônomo, produto da dinâmica de suas características individuais).

O que está em pauta, portanto, é a adoção, também na Psicologia Social, da postura construtivista (ISRAEL, 9, 1972) onde o sujeito é enfocado como produto e produtor da realidade social. Ao adotar esta ótica construtivista o objeto privilegiado da Psicologia Social passa a ser o processo de aquisição de conhecimentos no afã de dar sentido ao mundo - a construção social da realidade para usar a expressão cunhada por BERGER e LUCKMANN(2). Processo privilegiado minimamente devido à centralidade que assumem a introjeção e a transformação dos 
dados sociais no desenvolvimento do pensamento.

A aquisição do conhecimento, nesta perspectiva, é um processo ativo de construção em dois sentidos complementares. Em primeiro lugar, o sujeito é ativo porque ele dá sentido aos objetos sociais, materiais ou ideacionais que o cercam; ou seja, em última análise, ele constroi representações ou teorias sobre estes objetos. Em segundo lugar, ele é ativo porque cria, efetivamente, o mundo social através de sua atividade. Neste sentido o homem transforma a natureza e, ao transformá-la, gera as condições sociais para o processo de produção: a praxis no vocabulário marxista.

Estas duas dimensões, a atividade simbólica e a praxis, estão numa relação dialética uma vez que o conhecimento é a base da praxis e a praxis a forma de verificação do conhecimento. Como diz LEONTIEV (12) (1978):

\begin{abstract}
"se por um lado os significados atribuídos às palavras são produzidos pela coletividade no seu processar histórico e no desenvolvimento de sua consciência social e, como tal, se subordinam às leis histórica-sociais, por outro, os significados se processam e se transformam através de atividades e pensamentos de indivíduos concretos $\theta$ assim se subjetivam (adquirindo um sentido pessoal) na medida em que retornam para a objetividade sensorial do mundo que os cerca, através das ações que eles desenvolvem concretamente" (apud LANE, 11, 1984:33)
\end{abstract}

A perspectiva construtivista privilegia, portanto, tanto a relação dialética entre a esfera individual e social, quanto a relação dialética entre pensamento e atividade. É justamente pela ênfase dada a estes dois eixos que a abordagem denominada por Serge Moscovici (15) em 1961 de Representações Sociais vem assumindo uma função agregadora em Psicologia Social.

As representações sociais são formas de conhecimento prático - o saber do senso comum - que tem por função estabelecer uma ordem que permita aos indivíduos orientarem-se em seu mundo social e material e possibilitar, desta forma, a 
comunicação entre os membros de um mesmo grupo. Dado seu caráter eminentemente social - visto que o significado a elas atribuído advém do mundo social - é imperativo que elas sejam sempre remetidas: às condições de sua produção; às comunicações mediante as quais elas são veiculadas; e às funções a que servem na interação com o mundo social. Assim, embora acessadas através do discurso elas são elucidadas pelos nexos que estabelecem com o entorno social.

\section{PSICOLOGIA SOCIAL E SAÚDE}

Se a perspectiva construtivista é recente na Psicologia Social, mais recente ainda é ela nas aplicações ao campo da saúde onde, tradicionalmente, a psicologia tem atuado embasada numa ótica intra-individual.

Para entender esta afirmação necessário se faz pontuar a dupla interface da psicologia com a saúde: primeiramente como prática, atuando a partir do referencial clínico e centrada na experiência do paciente/cliente com sua doença. Em segundo lugar como teoria explicativa, contribuindo, juntamente com as demais disciplinas relevantes neste cenário interdisciplinar, para a compreensão do processo saúde/doença.

Em se tratando da contribuição da perspectiva construtivista da Psicologia Social à área da Saúde, é obvio que estaremos abordando apenas a segunda interface; embora óbvio também seja que a abordagem teórica pode - e deve - embasar a prática. Pode e deve, mas não o faz - no momento - talvez por constituir um corpo de conhecimentos ainda incipiente.

Ao ser pensada como disciplina explicativa, a Psicologia da Saúde, ao longo de sua breve história, reproduziu a situação existente na disciplina mãe. Partiu, 
inicialmente, de uma perspectiva intra-individual para a explicação do processo saúde/doença; passou, numa fase posterior, a incorporar o social de forma mecânica e, apenas recentemente, adotou uma postura mais dinâmica face ao social, abraçando uma postura construtivista.

Ao fazer referência à "breve história da Psicologia da Saúde" torna-se necessário abrir novo parêntese. Afinal, todos sabemos que desde tempos imemoriais, tanto no ocidente quanto no oriente, a vinculação entre comportamento e saúde, ou entre corpo e mente, fez parte da reflexão sobre a doença, especialmente em períodos históricos (ou a partir de visões de mundo) onde a doença foi equacionada com a ruptura do equilíbrio intra-indivíduo ou entre o indivíduo e o cosmos. Falar em "breve história" exige, pois, uma qualificação. Breve, aqui, referese ao esforço sistematizado de pesquisa, próprio à postura cientffica das modernas disciplinas. Neste sentido, as explicações do processo saúde/doença que englobam uma perspectiva psicológica tem uma história recente que remonta, segundo revisão feita por LIPOWSKI (13) (1986) à década de trinta.

\section{PSICOLOGIA E SAÚDE NA VERTENTE INTRA-INDIVIDUAL}

Retornando então às fases por que passou a Psicologia da Saúde na progressiva incorporação da dimensão social na explicação do processo saúde/doença, mencionamos anteriormente que, num primeiro momento, a explicação privilegiou, sem dúvida, a esfera intra-individual. Voltada à explicação do aparecimento da doença no organismo individual esta primeira vertente subsume duas correntes distintas: uma fortemente influenciada pela abordagem psicanalitica e a outra mais vinculada às teorias da personalidade.

A primeira corrente aqui identificada tem como conceito central a 
psicogênese da doença. Derivada da teoria psicanalítica tem como principal proponente o psicanalista Franz Alexander. A tese central de Alexander era de que os conflitos inconscientes não resolvidos entre os desejos e as forças antagonísticas do ego e do superego geravam tensões emocionais crônicas cujos correlatos fisiológicos podiam resultar em disfunção ou mesmo em mudanças estruturais em determinados órgãos do corpo. Uma nova versão para a velha e influente tese de que a emoção não domesticada gera doença. A Psicogênese foi a teoria predominante na medicina psicossomática entre 1930 e 1968, perdendo força, entretanto, à medida que se reconhecia a multicausalidade da doença e se re-situava a emoção como um dos elementos da resposta psicofisiológica do organismo aos inputs de informação do ambiente - e não mais como causa primária de determinadas reações somáticas.

A segunda corrente da vertente intra-individual, mais próxima às teorias da personalidade, também toma fôlego na década de trinta, especialmente através do trabalho de Helen Dunbar. O pressuposto central, no caso, é que existe uma relação entre certos tipos de personalidade e certas doenças. Atualmente o esforço de pesquisa nesta corrente centra-se especialmente em duas doenças da modernidade: o câncer e as doenças cardíacas. O câncer, objeto de análise de um ensaio de Susan Sontag (18)(1984) sobre as metáforas da doença, tem sido vinculado com a repressão das emoções, seja no sentido mais genérico de bloqueio de energias como no caso de Reich(16) - ou no sentido mais especffico de introversão como característica de personalidade - como no caso de Eysenck(6)(1966).

Já as doenças cardíacas, atualmente no epicentro da atividade de pesquisa nesta área, destacaram o papel da chamada personalidade "tipo A": uma constelação de características de comportamento explorada pelos pesquisadores na área de cardiologia desde a década de sessenta e que ocupa hoje lugar proeminente nas publicações especializadas em Psicologia da Saúde como aponta a revisão da 
literatura nesta área feita por Bennett e Carroll (1) em 1990. A personalidade tipo A agrega as características típicas da vida nos grandes centros urbanos: competitividade, hostilidade, pressão de tempo, impaciência, necessidade de autoatualização, tensão muscular, etc. Em suma, é esta a corrente responsável pelas manchetes recentes em jornais paulistas que afirmavam que a "hostilidade mata"... ou seja - lendo-se nas entrelinhas - faça terapia e viva mais tempo!!!

\section{ASPECTOS PSICOSSOCIAIS DO ADOECIMENTO}

A segunda vertente identificada neste ensaio enfatiza os aspectos psicossociais da cadeia multicausal responsável pelo surgimento da doença. Situamse aqui os estudos sobre os "eventos de vida" e sobre o stress a começar pela obra já clássica de WOFF(20) - Stress e Doença - publicada em 1953.

Esta vertente tornou-se particularmente popular em função dos avanços metodológicos que possibilitaram a mensuração das variáveis, a construção de indicadores e o seu tratamento estatístico através de técnicas multivariáveis em busca de correlações entre eventos estressantes na vida do indivíduo e o aparecimento da doença. É necessário ressaltar, de modo a prevenir os incautos, de que não se trata, nesta vertente, de apontar os aspectos patogênicos da vida social - aspecto este que é objeto de estudo da epidemiologia - mas de buscar nexos causais entre experiências de vida e 0 adoecer.

Foi no afã de desenvolver metodologias adequadas para análises quantitativas - tarefa tão popular nas ciências sociais da década de 50 e 60 - que surgiram os questionários estandardizado, como os de Holmes e Rahe (Schedule of Recent Experiences) que possibilitaram a elaboração de indicadores de stress. Foi 
esta vertente, em suma, a responsável pela popularização de mensagens emocionalmente ameaçadoras como a famosa conclusão de que o câncer tende a surgir entre seis e dezoito meses após a experiência de tensões críticas (como, por exemplo, a morte do companheiro).

Mas, como medir tensões críticas? Afinal, como apontou Brown (1981)(4) em sua crtica aos questionários sobre eventos de vida, o que conta não é a experiência em si mas o significado - o sentido pessoal - que ela tem para o indivíduo. Curiosamente, após tão valioso "insight", o que faz Brown? Dedica-se a reformular o questionário de Holmes e Rahe de modo a acessar o significado da experiência de forma quantificável!!

Corrente paralela, nesta vertente, e com sérias implicações do ponto de vista da medicalização de nossas vidas, enfoca mais particularmente os fatores objetivos do stress físico, procurando entender e, especialmente, prevenir os comportamentos de risco: fumar, comer alimentos inadequados, levar uma vida sedentária.

Fica evidente, sem dúvida, que esta segunda vertente está intrinsicamente relacionada às posturas de promoção da saúde e prevenção de doença. Afinal, é difícil, sem recorrer à psicoterapia, mudar características de personalidade. Mas no que diz respeito ao estilo de vida, a responsabilidade fica com o indivíduo e a responsabilidade, como já dizia Platão, faz parte da esfera de socialização. Assim, se a primeira vertente pertencia à esfera das emoções e das terapias, a segunda parece pertencer à esfera da educação. 


\section{SAÚDE/DOENÇA NA PERSPECTIVA CONSTRUTIVISTA}

Já a terceira vertente difere das demais em vários sentidos. Antes de mais nada, partindo da analogia das esferas, poderíamos afirmar que esta vertente privilegiando a perspectiva do paciente e não mais do médico ou do sistema de saúde - pertence sobretudo à esfera da conscientização. Há, ainda, uma segunda inversão importante. As duas primeiras vertentes privilegiam a explicação da doença a partir da explicitação da rede de causalidade: o que está em pauta é entender (e prevenir) o surgimento da doença. A terceira vertente, ao contrário, não tem por objetivo formular leis causais; a doença é vista como um fenômeno psicossocial, historicamente construído, e, como tal - é, sobretudo, um indicador da ideologia vigente sobre $o$ adoecer $e$ os doentes em uma determinada sociedade.

Tal postura implica em dois saltos qualitativos: primeiramente porque aborda a doença não apenas como uma experiência individual mas também como um fenômeno coletivo sujeito às forças ideológicas da sociedade. Em segundo lugar, por inverter a perspectiva deixando de privilegiar a ótica médica como único padrão de comparação legftimo e passando a legitimar, também, a ótica do paciente. Esta vertente, portanto, possibilita o confronto entre o significado (social) da experiência e o sentido (pessoal) que lhe é dado pelo indivíduo.

A terceira vertente enfatiza, assim, as representações do processo saúde/doença, procurando explicitar o substrato social das construções que determinados grupos ou sociedades fazem da doença e da saúde. Também nesta vertente é possível identificar várias correntes. A primeira corrente centra os esforços de pesquisa especificamente nas teorias do senso comum, ou seja, nas explicações da saúde/doença na interface entre os fatores sociais e psicobiológicos. Inserem-se nesta perspectiva alguns dos estudos clássicos sobre representações sociais. Por 
exemplo, a pesquisa de Claudine Herzlich (7), publicada na França em 1969, teve por objetivo estudar as representações da saúde/doença então vigentes. Representações que, de acordo com a análise realizada, estavam organizadas em torno de um núcleo figurativo constituído através da polarização de duas dicotomias: indivíduo/sociedade e atividade/inatividade. A doença, portanto, surgia do conflito entre o social (mediado pelo estilo de vida) e a resistência individual (a reserva de saúde própria a cada indivíduo). Paralelamente, a saúde representava a integração na sociedade, através da atividade (especialmente a atividade produtiva) enquanto a doença representava a exclusão da sociedade pela inatividade.

Outro exemplo relevante de pesquisa nesta corrente é o estudo de Denise Jodelet (1989)(10), também realizado na França, sobre as representações sociais da loucura em uma comunidade rural que integrava um sistema de albergamento de doentes mentais egressos de hospitais psiquiátricos. Neste estudo as representações pareciam se organizar através da polarização entre cérebro e nervos, como instâncias biológicas determinantes da doença mental. A articulação entre este núcleo figurativo e as suposições feitas a respeito das condições sociais e do período de vida em que a doença havia se manifestado gerou um complexo sistema de classificação que orientava a ação da comunidade estudada no trato aos doentes mentais ali albergados.

Dados surpreendentemente compatíveis, considerando as diferenças relativas ao contexto cultural em que os estudos foram realizados, foram obtidos em uma pesquisa realizada em Petrópolis, Rio de Janeiro, por Luiz Fernando Duarte (1988)(5). Também nesta pesquisa a representação do "nervoso" tem um locus físico que opõe cabeça (nervos) e corpo, oposição esta que é mediada por noções de resistência (como força e fraqueza) e de movimento (irritação, obstrução). 0 dado mais importante, talvez, é que também neste estudo as representações das perturbações nervosas evocavam um forte componente moral; uma instância 
axiológica que criava uma oposição entre o inocente - vítima das circunstâncias - e o fraco ou maldoso, revelando um terreno ainda virgem do ponto de vista da pesquisa psicossocial. Ou seja, as ordens morais imbricadas na construção dos saberes sobre saúde/doença.

A segunda corrente desta terceira vertente explora as interfaces entre a representação e o comportamento. Por exemplo, a relação entre a representação da doença e a auto-medicação ou, ainda, entre representações e a escolha de terapêuticas oficiais e/ou alternativas. Assim, na pesquisa realizada por Loyola (1984)(14) sobre a medicina popular fica bastante evidente que a definição da origem da doença - se doença do corpo ou da alma - orienta a escolha da terapêutica adequada - por exemplo, se é doença de médico ou de umbanda.

A terceira corrente, por sua vez, explora a interface entre o saber popular e o saber oficial. Incluiríamos nesta corrente os estudos referentes à difusão do saber oficial, tal como explorado na pesquisa de Moscovici (1978)(15) sobre a representação social da psicanálise na França na década de cinqüenta. Incluirfamos, também, os estudos sobre as inevitáveis tensões resultantes do confronto entre os dois tipos de saber como ocorre, por exemplo, nas interações entre médicos (ou outros profissionais da equipe de saúde) e paciente. A tf́tulo de ilustração valeria citar o clássico estudo de Boltanski (1969)(3) sobre as práticas de puericultura nas classes trabalhadoras francesas. Estudo sobre o autor aborda tanto a difusão dos conhecimentos oficiais e sua penetração no saber do senso comum, quanto as implicações deste saber popular para o "colóquio singular" entre médicos e pacientes das classes menos privilegiadas. 


\section{IMPLICAÇÕES}

Face ao salto qualitativo introduzido por esta terceira vertente - vertente que proponho ser mais compatível com a perspectiva construtivista - cabe perguntar qual é a relevância para a área da saúde pensada como o conjunto de práticas voltadas para a promoção da saúde e prevenção ou cura da doença. No meu entender são três as possíveis contribuições.

Em primeiro lugar, são as representações - como forma de conhecimento prático - que orientam a ação. Se quisermos influenciar a ação (seja esta ação a busca de atendimento, a auto-medicação ou até mesmo os estilos de vida) precisamos antes compreender o que embasa a ação. A palavra de ordem, no caso, não é educar mas conscientizar, tornando transparente o que era opaco e enfatizando os aspectos criativos do pensamento individual.

Em segundo lugar, como já havia apontado Brown (1) em sua critica aos estudos sobre eventos de vida, o que está em pauta é o sentido pessoal dado à experiência. Sentido este que está intimamente imbricado com as representações que se tem dos eventos em pauta.

Finalmente, retomando a questão da Psicologia como prática, merecem destaque as mudanças que vêm ocorrendo na inserção dos psicólogos nos serviços de saúde, especialmente no que diz respeito à sua atuação em serviços ambulatoriais e em unidades básicas. Estas novas formas de inserção pervertem a relação clínica tradicional e força os psicólogos a adotarem uma postura mais compatível com a Psicologia Comunitária. Tais transformações colocam a formação tradicional do psicólogo na berlinda, deixando transparecer as lacunas no que se refere aos conhecimentos necessários para embasar esta nova forma de atuação. Aqui também a perspectiva da construção social do conhecimento sobre saúde e doença pode 
trazer contribuições efetivas, diminuindo a distância social; possibilitando a compreensão da visão de mundo especffica dos diversos grupos sociais e motivando os psicólogos a buscarem formas de atuação mais compatfiveis com os objetivos do atendimento ao nível primário.

\section{REFERÊNCIAS BIBLIOGRÁFICAS}

1. BENNETT, P. \& CARROLL, D. Stress management approaches to the prevention of coronary heart disease. Brit. J. of clin. Psichol., 29:1-12, 1990.

2. BERGER, P. \& LUCKMANN, T. A construção social da realidade. Petrópolis, Vozes, 1978.

3. BOLTANSKI, L. Prime education et morale de classe. Paris, PUF, 1969.

4. BROWN, G.W. Life events, psychiatric disorder and physical illness. J. psychosom. Med., 25:461-73, 1981.

5. DUARTE, L.F.D. Da vida nervosa nas classes trabalhadoras urbanas. $2^{a}$ ed. Rio de Janeiro, Zahar/CNPq, 1988.

6. EYSENCK, H.J. \& RACHMAN, S. Dimensions of personality. In: SEMEONOFF, B., org. Personality assessment: selected readings. G.Britain Penguin Books, 1966,(p.) (cidade)

7. HERZLICH, C. Health and illness: a social psychological analysis. London, Academic Press, 1973.

8. IBANEZ, T. Henri, Serge and the next generation. Soc. Psychol. Newslet. (24):5-14, 1990-91.

9. ISRAEL, J. Stipulations and construction in the social sciences. In: ISRAEL, J. \& TANFEL, H. The context of social psychology: a critical assessment. London, Academic Press, 1972. páginas do capítulo

10. JODELET, D. Folies et representations sociales. Paris, PUF, 1989.

11. LANE, S. \& CODO, W., org. Psicologia social: o homem em movimento. São Paulo, Brasiliense, 1984.

12. LEONTIEV, A. Actividad, consciencia y personalid. Buenos Aires, Ed. Ciencias del Hombre, 1978. 
13. LIPOWSKY, Z.J. Psychosomatic medicine: past and present. Can. J. Psychiat., 31:2-21, 1986.

14. LOYOLA, M.A. Médicos e curandeiros: conflito social e saúde. São Paulo, Difel, 1984.

15. MOSCOVCl, S. A representação social da psicanálise. Rio de Janeiro, Zahar, 1978.

16. REICH, W. The function of the orgasm. London, Panther Books, 1970.

17. ROLNIK, S. Cartografia sentimental: transformações contemporâneas do desejo. São Paulo, Estação Liberdade, 1989.

18. SONTAG, S. A. Doença como metáfora. Rio de Janeiro, Graal, 1984.

19. TAJFEL, H. Social identity and intergroup relations. Cambridge, Cambridge University Press, 1982.

20. WOLFF, H.G. Stress and disease. Springfield, III., Charles C. Thomas, 1953. 